\title{
Verschillen in belangstellingsprofielen van vrouwelijke en mannelijke studenten geneeskunde
}

\author{
J.J.D.J.M. Rademakers, A.L.S. Bloemen, M.B.M. Soethout, J. Cohen-Schotanus, Th.J. ten Cate
}

\begin{abstract}
Samenvatting
Inleiding: In deze studie is nagegaan in hoeverre er verschillen zijn in de belangstellingsprofielen van vrouwelijke en mannelijke studenten geneeskunde ten aanzien van kenmerken van het medisch beroep, op welke kenmerken de verschillen betrekking hebben en of de voorkeuren zich ontwikkelen gedurende de studie.

Methode: De onderzoeksgegevens zijn afkomstig van een enquête onder studenten geneeskunde van het VUmc en het UMC Utrecht. In totaal vulden 2342 studenten de vragenlijst in (respons 79\%).
\end{abstract}

Resultaten: Bij driekwart van de beroepskenmerken is er een significant verschil tussen vrouwelijke en mannelijke studenten. De beroepskenmerken die vrouwen aantrekkelijker vinden dan mannen hebben te maken met psychosociale aspecten en zaken die de relatie met de patiënt betreffen. Bovendien is voor vrouwen de mogelijkheid om parttime te kunnen werken beduidend belangrijker. Mannen hebben vaker een voorkeur voor technische aspecten van het vak en voor kenmerken die te maken hebben met status.

Conclusieldiscussie: Na de coschappen worden de verschillen tussen vrouwelijke en mannelijke studenten kleiner. Met name de verschillen op psychosociaal gebied verdwijnen, doordat de vrouwen hun voorkeuren aanpassen en minder 'care'-gericht worden. (Rademakers JJDJM, Bloemen ALS, Soethout MBM, Cohen-Schotanus J, Cate Th.J. ten. Verschillen in belangstellingsprofielen van vrouwelijke en mannelijke studenten geneeskunde. Tijdschrift voor Medisch Onderwijs 2008;27(4):171-180.)

\section{Inleiding}

Sinds begin jaren negentig is in Nederland het aandeel van vrouwelijke studenten in de geneeskunde flink toegenomen. Op sommige medische faculteiten is inmiddels al $80 \%$ van de studenten vrouw. Ook in andere landen vindt een stijging van het aantal vrouwelijke studenten geneeskunde plaats.

Verschillende studies zijn gedaan naar de gevolgen van deze 'feminisering' van de geneeskunde. Bij de onderzoeken die zich richten op de beroepscarrière van de studenten vallen twee zaken op. In de eerste plaats het feit dat de verdeling van vrouwen en mannen over de verschillende spe- cialismen niet gelijkmatig is. ${ }^{1-3}$ Vooral in de zogenaamde technische beroepsgroepen, zoals de snijdende vakken, zijn er nog steeds meer mannen dan vrouwen te vinden. Onderzoek naar de oorzaken van deze ongelijke verdeling wijst op een verschil in datgene wat vrouwen en mannen aantrekkelijk vinden in het beroep en in de functie van arts. Verschillende studies tonen aan dat vrouwelijke studenten arts willen worden vanwege mensgerichte, humanistische en altruïstische redenen terwijl de mannelijke studenten meer gemotiveerd worden door financiële overwegingen, prestige en wetenschappelijke en technische redenen. ${ }^{2}$ Vrouwen hebben 
een ander beeld van wat een ideale arts is dan mannen. ${ }^{24-5}$ Zij richten zich meer op de 'care'-aspecten terwijl mannen meer 'cure'-georiënteerd zijn. ${ }^{4}$ Niet in alle studies worden echter grote verschillen in motivatie en attitude gevonden tussen vrouwelijke en mannelijke studenten geneeskunde. ${ }^{2}$ Het valt op dat naast belangstelling vrouwen hun keuze voor een specialisme ook laten afhangen van hun persoonlijke omstandigheden, met name van de mogelijkheid om werk en privé (gezin) te combineren. ${ }^{6-9} \mathrm{Bij}$ mannen is dit ook het geval, maar in geringere mate dan bij vrouwen. Ook maakt de traditioneel mannelijke werkcultuur in bepaalde specialismen het minder aantrekkelijk voor vrouwen om die richting te kiezen of is het moeilijker voor hen om in die specialismen verder te groeien. ${ }^{3}$

Een tweede opvallend feit is dat vrouwen ondervertegenwoordigd zijn in de hogere regionen van de professie..$^{1-3}$ Twee mogelijke verklaringen hiervoor zijn dat vrouwen beroepskeuzes maken die minder gericht zijn op het maken van carrière (zij werken vaker parttime) en dat zij minder belangstelling hebben voor de hogere functies (andere interesses, minder competitief gedrag). Een derde verklaring wordt in de literatuur ook wel 'het glazen plafond' voor vrouwen genoemd. De nog overwegend mannelijke cultuur in de hogere regionen van de geneeskunde maakt het moeilijker voor vrouwen aan de mannelijke normen en waarden, die hierin gelden, te voldoen. Ook het gebrek aan vrouwelijke voorbeelden wordt als verklaring genoemd voor het lage aantal vrouwen in de hogere functies. ${ }^{10}$

De eerste ontwikkeling (de ongelijke verdeling van mannen en vrouwen over de specialismen) - ook wel 'horizontale segregatie' genoemd - zou op de lange termijn kunnen leiden tot een tekort aan artsen in bepaalde specialismen. Daar staat tegenover dat bepaalde belemmerende factoren (zoals een traditioneel mannelijke werkcultuur) in de loop van de tijd door de instroom van vrouwen kunnen verminderen. Wel blijft dan de vraag van de individuele voorkeur: vinden vrouwelijke en mannelijke studenten geneeskunde andere aspecten van het beroep interessant? En zijn deze verschillen consistent gedurende de hele studieperiode of hebben belangrijke ervaringen (zoals coschappen) invloed op deze voorkeuren? Uit sommige onderzoeken ${ }^{24-5}$ blijkt namelijk dat de verschillen tussen vrouwen en mannen in de loop van de studie geneeskunde kleiner worden. Naarmate de studie vordert wordt bijvoorbeeld zowel bij vrouwen als bij mannen de belangstelling voor psychosociale onderwerpen, en de mate waarin men patiënt-georiënteerd is, minder (al blijven vrouwen hier wel hoger op scoren dan mannen).4-5 Eerder Nederlands onderzoek toonde echter aan dat gender geen invloed heeft op de ontwikkeling van de attitude. ${ }^{11}$

Het doel van dit onderzoek is na te gaan in hoeverre er verschillen zijn in de belangstellingsprofielen van vrouwelijke en mannelijke studenten geneeskunde ten aanzien van kenmerken van het medisch beroep, en op welke kenmerken eventuele verschillen betrekking hebben. Tevens wordt gekeken naar de ontwikkeling van deze belangstellingsprofielen gedurende de studie.

\section{Methode}

In deze studie is gebruik gemaakt van gegevens die verkregen zijn door middel van een enquête, die in het studiejaar 2002/2003 gehouden is onder alle studenten geneeskunde van het VUmc en het UMC Utrecht $(n=2928)$. In totaal vulden 2342 studenten de vragenlijst in (bruto respons $80 \%$ ). Van de respondenten waren er 
491 eerstejaars (respons 81\%), 1323 tweede- en derdejaars zonder ervaring met coschappen ( $85 \%$ ) en 528 vierde- en vijfdejaars met ervaring met coschappen (69\%). ${ }^{12}$ Omdat niet op alle vragenlijsten het geslacht was ingevuld bleven er 2326 over voor analyse (netto respons 79\%). De enquête werd door 791 mannen (34\%) en 1535 vrouwen (66\%) ingevuld. Deze percentages kwamen overeen met de verdeling binnen de gehele populatie van studenten geneeskunde, zowel bij beide universiteiten als in het algemeen. ${ }^{12}$

In de enquête is aan de studenten gevraagd om van 47 beroepskenmerken aan te geven in hoeverre zij deze aantrekkelijk zouden vinden voor hun toekomstige beroep. De vragenlijst was gebaseerd op literatuurstudie en eerder onderzoek met focusgroepen naar de beroepspreferentie van studenten. ${ }^{13}$ De beroepskenmerken hebben betrekking op vier domeinen:

- vereiste kennis en vaardigheden

- aard van het medisch professioneel handelen

- type patiënten, contacten en aandoeningen

- kenmerken van het dagelijkse werk

De classificatie liep van 1 tot 5 ( 1 = zeer weinig aantrekkelijk en 5 = zeer aantrekkelijk). Om de verschillen scherper naar voren te laten komen werd er voor de analyse voor gekozen om deze schaal terug te brengen tot een dichotome $0-1$ schaal $(0=$ niet aantrekkelijk en 1 = aantrekkelijk), waarbij de scores 1 tot 4 van de oorspronkelijke classificatie in schaal 0 vallen en alleen de score 5 in schaal 1 valt. De gemiddelde scores bleken namelijk vrijwel steeds boven de 3.0 te liggen en op veel items (19) zelfs boven de 4.0.

De gegevens werden in vier groepen verdeeld om de invloed van de studie te beoordelen:
- alle studiejaren

- (begin) eerste studiejaar

- vlak voor de coschappen / eind derde studiejaar

- net na de coschappen van jaar 4 en 5 / eind vijfde studiejaar

Voor deze indeling is gekozen omdat verondersteld werd dat de kliniekervaring de gelegenheid geeft om verwachtingen en voorkeuren te toetsen aan de praktijk en dat juist daardoor mogelijk veranderingen in het profiel kunnen optreden.

De analyses ten aanzien van verschillen in voorkeuren met betrekking tot beroepskenmerken tussen vrouwelijke en mannelijke studenten geneeskunde werden uitgevoerd op de totale onderzoekspopulatie en voor de drie groepen afzonderlijk. Door middel van chi-kwadraat toetsen werd de statistische significantie van de verschillen tussen vrouwen en mannen nagegaan.

\section{Resultaten}

Uit analyse van de gegevens van de totale onderzoekspopulatie $(n=2326)$ blijkt dat er bij 33 van de 47 beroepskenmerken een significant verschil bestaat tussen de voorkeuren van vrouwen en mannen. Dat is bij bijna driekwart van de beroepskenmerken. De voornaamste gebieden waarop deze verschillen liggen betreffen psychosociale en technische aspecten.

Tabel 1 laat de verschillen tussen vrouwen en mannen zien en de mate waarin ze bepaalde beroepskenmerken aantrekkelijk vinden. Alle + + laten die beroepskenmerken zien die vrouwen aantrekkelijker vinden dan mannen. De - - laten zien welke kenmerken mannen aantrekkelijker vinden dan vrouwen. Het aantal + + en - staat voor het significantieniveau van de verschillen: hoe meer ++ of - - des te groter het significantieniveau. 
Sekseverschillen in belangstellingsprofielen | J.J.D.J.M. Rademakers et al.

Tabel 1. Voorkeuren voor beroepsaspecten naar genderverschillen* en significantieniveau.

\begin{tabular}{cccc}
\hline Alle cohorten & Studiejaar 1 & $\begin{array}{c}\text { Voor de } \\
\text { coschappen }\end{array}$ & $\begin{array}{c}\text { Na de } \\
\text { coschappen }\end{array}$ \\
\hline
\end{tabular}

Vereiste kennis en vaardigheden:

Anatomische kennis

Chemische, fysische en biologische kennis

Kennis van pathologie

Kennis van epidemiologie

Farmacotherapeutische kennis

Kennis van psychosociale en culturele achtergronden

Kennis over de organisatie van de gezondheidszorg

Kunnen communiceren

Handvaardigheid

Wetenschappelijke oriëntatie

Redeneervaardigheid

Improvisatietalent

Handigheid met apparatuur

Aard van het medisch professioneel handelen:

Voorlichten

Voorkomen van ziekte

Doorverwijzen

Diagnostiek

Behandelen

Bestrijden van pijn en ongemak

Begeleiden bij ziekte

Type patiënten, contacten en aandoeningen:

Jonge patiënten

Oude patiënten

Langdurige relatie met patiënt

Eenvoudige aandoeningen

Meerdere aandoeningen tegelijk

Terminale aandoeningen

Acute aandoeningen

Chronische aandoeningen

Psychosociale aandoeningen

Gezonde personen

$\begin{array}{ccc}+++ & ++ & + \\ +++ & + & + \\ + & & +++ \\ +++ & ++ & ++\end{array}$

Kenmerken van het dagelijkse werk:

Routinewerk

Diversiteit

Fysiek werk

Denkwerk

Praatwerk

Teamwerk

Technisch nauwkeurig werk

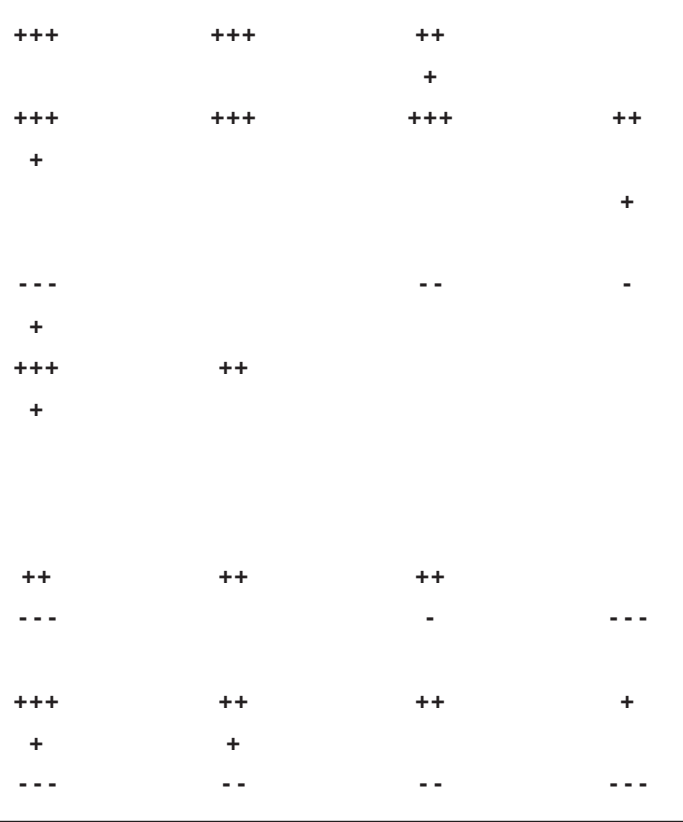


Sekseverschillen in belangstellingsprofielen | J.J.D.J.M. Rademakers et al.

\begin{tabular}{|c|c|c|c|c|}
\hline & Alle cohorten & Studiejaar 1 & $\begin{array}{c}\text { Voor de } \\
\text { coschappen }\end{array}$ & $\begin{array}{c}\text { Na de } \\
\text { coschappen }\end{array}$ \\
\hline Vertrouwensrelatie opbouwen met patiënten & +++ & +++ & +++ & + \\
\hline Zichtbare resultaten & & & & -- \\
\hline Overleg met collega's en anderen & ++ & & + & \\
\hline Lange werkdagen & -- & -- & & \\
\hline \multicolumn{5}{|l|}{ Veel spreekuren } \\
\hline Stressvol werk & -- & & & \\
\hline \multicolumn{5}{|l|}{ Onregelmatig werk } \\
\hline Parttime werkmogelijkheid & +++ & +++ & +++ & +++ \\
\hline Hoog inkomen & -- & -- & - & - \\
\hline Hoog aanzien & -- & -- & & -- \\
\hline$m>v$ en $p<0.001$ & -- & & & \\
\hline $\mathrm{m}>\mathrm{v}$ en $\mathrm{p}<0.01$ & -- & & & \\
\hline $\mathrm{m}>\mathrm{v}$ en $\mathrm{p}<0.05$ & - & & & \\
\hline$M<v$ en $p<0.001$ & +++ & & & \\
\hline$M<v$ en $p<0.01$ & ++ & & & \\
\hline$M<v$ en $p<0.05$ & + & & & \\
\hline
\end{tabular}

$*(V>M=+$ en $M>V=-)$

Uit dit overzicht komt duidelijk naar voren dat vrouwen en mannen een groot aantal beroepskenmerken zeer verschillend waarderen. Hieronder volgt een beschrijving per onderdeel, gevolgd door een top vijf van de beroepskenmerken die mannen en vrouwen het aantrekkelijkst vinden.

\section{Vereiste kennis en vaardigheden}

Vrouwen vinden vooral vereiste kennis van pathologie $(\mathrm{p}<0.01)$ en van psychosociale en culturele achtergronden $(\mathrm{p}<0.001)$ aantrekkelijk. Mannen geven de voorkeur aan anatomische $(\mathrm{p}<0.001)$ en chemische, fysische en biologische kennis $(\mathrm{p}<0.05)$. Wat vaardigheden betreft vinden vrouwen vooral het kunnen communiceren $(\mathrm{p}<0.001)$ aantrekkelijk. Mannen zien meer in handvaardigheid $(\mathrm{p}<0.01)$, wetenschappelijke oriëntatie $(\mathrm{p}<0.01)$, improvisatietalent $(\mathrm{p}<0.001)$ en handigheid met apparatuur $(\mathrm{p}<0.001)$ als vereiste vaardigheden.

\section{Aard van het medisch professioneel handelen}

Kenmerken in het medisch professioneel handelen die vrouwen aantrekkelijker vinden dan mannen zijn het voorlichten $(\mathrm{p}<0.001)$, het voorkómen van ziekte $(\mathrm{p}<0.001)$, de diagnostiek $(\mathrm{p}<.05)$, het bestrijden van pijn en ongemak $(p<0.001)$ en het begeleiden bij ziekte $(\mathrm{p}<0.001)$. Mannen geven de voorkeur aan het doorverwijzen en behandelen, maar het verschil met vrouwen is hier niet statistisch significant.

\section{Type patiënten, contacten en aandoeningen}

In vergelijking met mannen vinden de vrouwelijke studenten jonge patiënten $(\mathrm{p}<0.001)$ aantrekkelijker. Zij hebben meer belangstelling voor langdurige patiëntrelaties $(\mathrm{p}<0.001)$ en voor contacten met gezonde personen $(\mathrm{p}<0.05)$. Qua 
aandoeningen hebben vrouwen liever te maken met eenvoudige aandoeningen $(\mathrm{p}<0.05)$, chronische aandoeningen $(\mathrm{p}<0.05)$ en psychosociale aandoeningen $(\mathrm{p}<0.001)$. Mannen vinden acute aandoeningen aantrekkelijker $(\mathrm{p}<0.001)$.

\section{Kenmerken van het dagelijkse werk}

Vrouwen zoeken in hun dagelijkse werk meer naar diversiteit $(\mathrm{p}<0.01)$ en praatwerk $(\mathrm{p}<0.001)$. Ze hechten meer waarde aan het opbouwen van een vertrouwensrelatie met patiënten $(\mathrm{p}<0.001)$ en aan overleg met collega's en anderen $(\mathrm{p}<0.01)$. Ook de mogelijkheid van parttime werken vinden vrouwen belangrijker $(\mathrm{p}<0.001)$. Mannen doen liever technisch nauwkeurig werk $(\mathrm{p}<0.001)$ en hebben minder moeite met lange werkdagen $(\mathrm{p}<0.001)$ dan vrouwen. Ook hechten zij meer waarde aan een hoog inkomen $(\mathrm{p}<0.001)$ en een hoog aanzien $(\mathrm{p}<0.001)$.

\section{Top vijf van beroepskenmerken die vrou- wen aantrekkelijker vinden dan mannen}

De volgende beroepskenmerken worden door vrouwen het meest gewaardeerd:

1. parttime werkmogelijkheid $(<0.001)$

2. jonge patiënten $(<0.001)$

3. opbouwen van vertrouwensrelatie met patiënten $(<0.001)$

4. langdurige relatie met patiënt $(<0.001)$

5 . kunnen communiceren $(<0.001)$

\section{Top vijf van beroepskenmerken die man-} nen aantrekkelijker vinden dan vrouwen

De volgende beroepskenmerken worden door mannen het meest gewaardeerd:

1. technisch nauwkeurig werk $(<0.001)$

2. handigheid met apparatuur $(<0.001)$

3. hoog aanzien $(<0.001)$

4. improvisatie $(<0.001)$

5. hoog inkomen $(<0.001)$
In tabel 1 is ook te zien dat naarmate de studie vordert de verschillen tussen vrouwen en mannen veranderen.

In studiejaar 1 zijn significante verschillen tussen vrouwen en mannen te zien bij 19 van de 47 beroepskenmerken. Hiervan vinden vrouwen veertien kenmerken en mannen vijf kenmerken aantrekkelijker. In de groep vóór aanvang van de coschappen is er een significant verschil bij 21 beroepskenmerken: zestien kenmerken worden aantrekkelijker gevonden door vrouwen en vijf door mannen. De groep na de coschappen toont op 16 kenmerken een significant verschil tussen vrouwen en mannen: vrouwen vinden zes kenmerken aantrekkelijker en mannen tien kenmerken. Er is dus een ontwikkeling waarbij de aanvankelijke verschillen tussen vrouwelijke en mannelijke studenten geneeskunde eerst nog verder toenemen tot aan de coschappen, om na de coschappen tot een lager niveau dan bij de start van de studie te dalen.

Het zijn echter niet altijd dezelfde beroepskenmerken waarop de verschillen betrekking hebben. Slechts bij acht van de 47 kenmerken blijft het verschil tussen vrouwen en mannen gedurende de hele studieperiode significant. Dit is het geval bij:

- kennis van psychosociale en culturele achtergronden ( $\mathrm{v}>\mathrm{m})$

- handigheid met apparatuur $(\mathrm{m}>\mathrm{v})$

- langdurige relatie met patiënt $(\mathrm{v}>\mathrm{m})$

- praatwerk $(\mathrm{v}>\mathrm{m})$

- technisch nauwkeurig werk $(\mathrm{m}>\mathrm{v})$

- opbouwen van vertrouwensrelatie met patiënt $(v>m)$

- parttime werkmogelijkheid $(\mathrm{v}>\mathrm{m})$

- hoog inkomen $(\mathrm{m}>\mathrm{v})$

In figuur 1 is te zien welke beroepskenmerken gedurende de studie aantrekkelijker zijn voor vrouwen (balk naar boven) en mannen (balk naar beneden) en hoe deze voorkeur gedurende de studie verandert. De percentages geven aan hoeveel 
- jaar 1

- voor coschappen

$\square$ - na coschappen

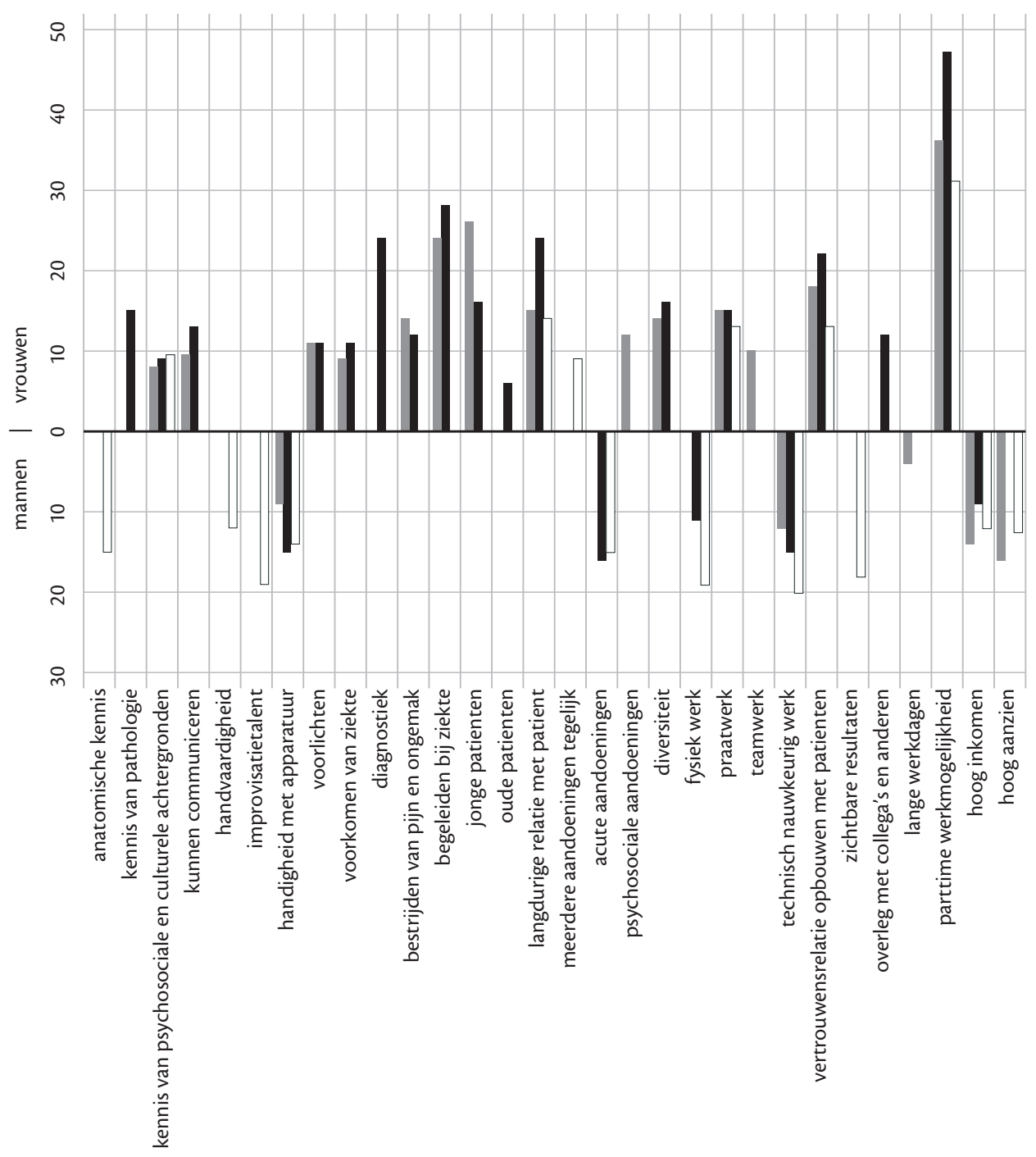

Figuur 1. Aantal studenten met duidelijke voorkeur voor 47 beroepsaspecten naar gender en studieduur (in \%). 
procent van de vrouwelijke en mannelijke studenten het betreffende kenmerk aantrekkelijk vinden. De beroepskenmerken die op geen enkel moment gedurende de studie significant verschillend zijn voor vrouwen en mannen zijn voor de overzichtelijkheid weggelaten uit deze figuur. Kennelijk wordt de uitgesproken voorkeur voor bepaalde beroepskenmerken die vrouwen vóór aanvang van de coschappen hebben minder door de ervaring in de kliniek. Met name waar het de aanvankelijke belangstelling betreft voor het kunnen communiceren en de aard van de werkzaamheden (voorlichten, voorkomen van ziekte, bestrijden van pijn en ongemak, begeleiden bij ziekte) valt het verschil weg en gaan de vrouwelijke studenten qua belangstelling meer op hun mannelijke collega's lijken. Mannen worden door de klinische ervaring juist gestimuleerd in hun voorkeur voor kenmerken als anatomische kennis, handvaardigheid, improvisatietalent, fysiek en technisch nauwkeurig werk en zichtbare resultaten.

\section{Conclusie en discussie}

Deze studie bevestigt eerdere studies waarin een verschil werd gevonden tussen datgene wat vrouwen en dat wat mannen aantrekt in het beroep van arts. Bij driekwart van de beroepskenmerken in ons onderzoek is er een significant verschil tussen de vrouwelijke en de mannelijke studenten. Als we kijken naar de top vijf van de beroepskenmerken die vrouwen aantrekkelijker vinden dan mannen dan gaat het om psychosociale aspecten en zaken die de relatie met de patiënt betreffen. Bovendien is voor vrouwen de mogelijkheid om parttime te kunnen werken beduidend belangrijker. Bij mannen heeft die top vijf meer te maken met technische aspecten van het vak en kenmerken die betrekking hebben op status.
Een gedetailleerdere blik laat zien dat de meeste kenmerken waarvan blijkt dat na de coschappen de verschillen verdwijnen, deze met name op psychosociaal gebied liggen (communicatie, voorlichten, begeleiden). Deze aspecten werden vóór de coschappen positiever beoordeeld door vrouwen. Mannen gaan deze kenmerken niet aantrekkelijker vinden, terwijl zij voor vrouwen wel minder aantrekkelijk worden. De ervaring in de kliniek leidt er niet zozeer toe dat de mannen 'vervrouwelijken' (in de zin van meer 'care'- en patiëntgericht worden) maar wel dat de vrouwen hun voorkeuren aanpassen. Een verklaring kan zijn dat zij in de klinische praktijk niet of slechts beperkt mogelijkheden zullen ervaren om met die aspecten van het beroep bezig te zijn die ze zo aantrekkelijk vonden. Een manier om met een eventuele discrepantie tussen wens en realiteit om te gaan is het bijstellen van de voorkeuren, in de richting die de mannelijke studenten al eerder hadden. Een andere verklaring voor het feit dat vrouwen minder 'care'-gericht worden, kan zijn dat deze houding in de praktijk als minder professioneel wordt beoordeeld door collega's en supervisoren. In die zin kan de traditionele werkcultuur voor vrouwelijke artsen in opleiding belemmerend werken op de door hen gewenste taakinvulling.

Vrouwen vinden mogelijkheden voor parttime werk duidelijk belangrijker dan mannen, maar ook mannen vinden lange werkdagen niet aantrekkelijk. Het lijkt er op dat niet alleen gender maar ook de generatie van invloed is op de mate waarin men het werk als arts centraal wil stellen in het leven. Ook andere studies ondersteunen deze bevinding. Een Amerikaanse studie naar de oorzaken van de dalende interesse in chirurgische beroepen toonde aan dat zowel gender als generatie hierbij een rol spelen. ${ }^{6}{ }^{14}$ Het willen hebben van tijd voor een gezin speelt bijvoorbeeld een 
grotere rol voor vrouwen in de keuze wel of geen opleiding tot chirurg te volgen, maar ook voor mannen speelt dit argument mee. Andere studies tonen nog sterker aan dat niet gender maar vooral generatie de oorzaak is van het feit dat steeds meer afgestudeerden (mannen evenzeer als vrouwen) kiezen voor een specialisme met een regelmatige levensstijl waarbij ze zelf controle hebben over de werktijden. ${ }^{7-9}$ Vrouwen kozen zelfs vaker dan mannen voor een specialisme met onregelmatige tijden (zoals gynaecologie). ${ }^{7}$

Dit onderzoek heeft enkele beperkingen. Het is verricht onder studenten van twee medische faculteiten in Nederland. Daardoor zijn de resultaten mogelijk niet direct generaliseerbaar naar de hele populatie studenten geneeskunde in Nederland (of buitenland). Bovendien is deze studie een dwarsdoorsnede onderzoek. Een longitudinaal onderzoek onder studenten geneeskunde zou een 'generatie'-verschil onder studenten kunnen uitsluiten.

Gender speelt zeker een rol in de belangstellingsprofielen en de latere beroepskeuze. Behalve gender kunnen ook competenties, praktijkervaringen en rolmodellen een invloed hebben op de beroepskeuze. Kilminster et al. ${ }^{2}$ stellen in hun artikel dat het belangrijk is om te kijken wanneer en waar gender een rol gaat spelen in het onderwijs en in de carrièrekeuze in plaats van alleen te kijken naar de verschillen tussen vrouwen en mannen. Toekomstig onderzoek zou longitudinaal van aard moeten zijn en zich moeten richten op de ontwikkeling van de beroepskeuze en de interactie met het belangstellingsprofiel en andere factoren.

\section{Literatuur}

1. Allen I. Women doctors and their careers: what now? BMJ 2005; 33:569-572.

2. Kilminster S, Downes J, Gough B, MurdochEaton D, Roberts T. Women in medicine - is there a problem? A literature review of the changing gender composition, structures and occupational cultures in medicine. Med Educ 2007; 41:39-49.

3. Reed V., Buddeberg-Fischer B. Career obstacles for women in medicine: an overview. Med Educ 2001; 35:139-147.

4. Verdonk P, Harting AJ, Lagro-Janssen TLM. Does equal education generate equal attitudes? Gender differences in medical students' attitudes towards the ideal physician. Teaching and Learning in Medicine 2007; 19(1): 9-13.

5. Wolochuk W, Harasym PH, Temple W. Attitude change during medical school: a cohort study. Med Educ 2004;38: 522-534.

6. Sanfey HA, Saalwachter-Schulman AR, NyhofYoung JM, Eidelson B, Mann BD. Influences on medical student career choice: gender or generation? Arch Surg 2006;14:1086-1094.

7. Lambert EM, Holmboe ES. The relationship between specialty choice and gender of U.S. medical students. Acad Med 2005;80:797-802.

8. Dorsey ER, Jarjoura D, Rutecki GW. The influence of controllable lifestyle and sex on the specialty choices of graduating U.S. medical students, 1996-2003. Acad Med 2005;80:791-796.

9. Heiligers PhJM, Hingstman L. Career preferences and the work-family balance in medicine: gender differences among medical specialist. Social Science and Medicine 2000;50:1235-1246.

10. McManus IC, Sproston KA. Women in hospital medicine in the United Kingdom: glass ceiling, preference, prejudice or cohort effect? J of Epid and Comm Health 2000;54(1):10-6.

11. Batenburg V, Smal JA, Lodder A, Melker de RA. Are professional attitudes related to gender and medical specialty? Med Educ 1999;33:489-492.

12. Soethout MBM. Career preference of medical students and career choice of recent graduates [dissertation]. Amsterdam: Vrije Universiteit; 2007.

13. Nieuwhof MG, Rademakers JJDJM, Kuyvenhoven MM, Soethout MBM, Ten Cate ThJ. Students conceptions of the medical profession; an interview study. Med Teach 2005;27(8):709-14.

14. Wendel TM, Godellas CV, Prinz RA. Are there gender differences in choosing a surgical career? Surgery 2003;134: 591-8.

De auteurs:

Mw. dr. J.J.D.J.M. Rademakers was ten tijde van het onderzoek programmaleider Kwaliteitszorg, Ontwikkeling en Onderzoek bij het Expertisecentrum voor Onderwijs en Opleiding van het UMC Utrecht. Momenteel is ze programmaleider Vraaggestuurde zorg bij het NIVEL, Nederlands instituut voor onderzoek van de gezondheidszorg te Utrecht.

Mw. A.L.S. Bloemen is student geneeskunde bij het UMC Groningen en was in de periode mei - juli 2007 als onderzoeksstagiaire verbonden aan het Expertisecentrum voor Onderwijs en Opleiding van het UMC Utrecht. 
Sekseverschillen in belangstellingsprofielen | J.J.D.J.M. Rademakers et al.

Dr. M.B.M. Soethout is werkzaam als onderwijscoördinator bij de afdeling Sociale Geneeskunde van het VUmc Amsterdam.

Mw. dr. J. Cohen-Schotanus is hoofd van het Centrum Innovatie en Onderzoek Medisch Onderwijs van het UMC Groningen.

Prof. dr. Th.J. ten Cate is directeur van het Expertisecentrum voor Onderwijs en Opleiding van het UMC Utrecht.
Correspondentieadres:

Mw. dr. Jany Rademakers, NIVEL, postbus 1568, 3500

BN Utrecht.E-mail: j.rademakers@nivel.nl

Belangenconflict: geen gemeld.

Financiële ondersteuning: geen gemeld.

\section{Summary}

Introduction: We examined differences between female and male medical students in their preferences relating to the medical profession, whether these differences are related to specific characteristics of the medical professions, and whether these preferences change in the course of their medical studies.

Method: A questionnaire was administered to medical students at VU Medical Center, Amsterdam and University Medical Center, Utrecht, both in the Netherlands. A total of 2342 students returned the questionnaire (79\% response).

Results: A significant difference between the preferences of female and male students was found for three quarters of the characteristics of the medical profession in the questionnaire. The female students showed a preference for psychosocial aspects and aspects concerning the doctor-patient relationship. Being able to work part-time was considerably more important to the female students. The male students demonstrated a stronger preference for the technical aspects of medicine and for aspects relating to social status.

Conclusion/discussion: After the clinical clerkships the differences between female and male students were diminished. This applies specifically to differences with respect to psychosocial aspects, with the female students becoming less care oriented. (Rademakers JJDJM, Bloemen ALS, Soethout MBM, Cohen-Schotanus J, Cate ThJ ten. Differences between male and female medical students in preferences relating to aspects of the medical profession. Dutch Journal of Medical Education 2008;27(4):171-180.) 